\title{
An Examination through Conjoint Analysis of the Preferences of Students Concerning Online Learning Environments According to Their Learning Styles
}

\author{
Gökhan DAĞHAN ${ }^{1} \&$ Buket AKKOYUNLU ${ }^{1}$ \\ ${ }^{1}$ Department of Computer Education and Instructional Technology, Faculty of Education, Hacettepe University, \\ Ankara, Turkey \\ Correspondence: Gökhan Dağhan, Department of Computer Education and Instructional Technology, Hacettepe \\ University, Ankara, Turkey. Tel: 90-312-297-7176. E-mail: gokhand@hacettepe.edu.tr
}

Received: May 10, 2012

Accepted: May 18, 2012 Online Published: June 25, 2012

doi:10.5539/ies.v5n4p122

URL: http://dx.doi.org/10.5539/ies.v5n4p122

\begin{abstract}
This study examines learning styles of students receiving education via online learning environments, and their preferences concerning the online learning environment. Maggie McVay Lynch Learning Style Inventory was used to determine learning styles of the students. The preferences of students concerning online learning environments were detected through the prioritization of determined main factors and sub-factors. Conjoint analysis, which is a multivariate statistical method, was employed in this study. The prepared conjoint questionnaire was administered both to the entire research group and to visual, auditory and kinesthetic style learning student groups separately. The findings obtained were interpreted by matching with their learning styles. It was concluded that online learning students attached great importance to the employed technology characteristic and to the student-administrator interaction. Considering general of the students, the synchronization or asynchronization of mode of communication and the existence or non-existence of technical support in the prepared environment were not considered important. It was concluded that as the learning styles of students varied, their views about other variables, the interaction preferences in the online learning environment in particular, also differed. Learning styles of students and their preferences concerning the learning materials also showed a parallelism.
\end{abstract}

Keywords: online learning, learning style, conjoint analysis, student preferences

\section{Introduction}

Today, the rapid and ever increasing development and the advances in technology affect business lives, social environments and the modes of communication between individuals and changes their ways of life. The increase in the amount of available knowledge and development and rapid progress of technological opportunities have orientated individuals to seek different learning strategies. Considering the transformation of the social structure into an information society, it is now possible for individuals to learn by obtaining information and constructing it in their own ways. Both the transformation of society into an information society and the emergence of different learning strategies created to the concept of "online learning".

Learning review of the literature indicates a wide range of definitions for online learning (Ally, 2004). Ally (2004) regards online learning as environments in which the Internet is used to access learning materials, which allows for the establishment of an interaction between the content, the environment administrator and other students, in which technical support can be provided throughout the learning process. This enables students to construct and internalize appropriate knowledge of the subject which develops through the learning experiences, becoming more effective as it develops.

An overall examination of the definitions show that online learning allows time and space for independent learning, it makes use of a networking environment, the Internet, and it enables students to gain and internalize knowledge through progressing at their own individual learning speeds, and makes it possible to interact with other students, learning environment and the environment administrator. It was reported that a high quality online learning environment would provide students with a series of learning opportunities and could pave the way for life-long learning for its students (Bueno, 2005). In these environments the learning styles of the 
students also become important.

\subsection{Learning Style}

Introduced by Dunn in the 1960s, the concept of a learning style was created on the assumption that students learn in modes that are different to each other. Many educational researchers have examined this topic and introduced a wide range of learning style models. The great majority of these models are based on the principle that all individuals are capable of learning, but their modes of learning vary. Examination of various models developed for learning styles, which are one of the most important individual characteristics, showed that each model has different approaches. While some models classify individuals according to their mental processes, a physical characteristic-based classification is observed in others. According to the Dunn, who contributed to the literature with many studies on learning styles over long years, there are several definitions of learning styles. Dunn defines it as "the ways in which each learner begins to concentrate on, process, and retain new and difficult information that is unique to each learner" (Dunn and Dunn, 1993). While Davis (1993) describes the concept of learning style as different preferences in the methods of individuals for collecting, organizing, thinking about and interpreting knowledge, Felder (1996) defines it as the personal differences of individuals in obtaining and processing knowledge.

Analysis of different definitions indicates that learning styles are unique to each individual. Each individual may have different approaches even when learning about events and phenomena, in the same space and at the same time, through their internalization processes. Course content and teaching activities should be devised taking into account the learning styles of students, as there are always different abilities, interests and attitudes regardless of the dimension in which the learning styles of the students are evaluated. There are many studies in the relevant literature reporting that both the academic achievements and the self-confidences of students increase thanks to the course content which is designed based-on the learning styles of the students (Dunn et al, 1990; Ayersman, 1996; Matthews, 1996; Snyder, 2000). According to Biggs (2001), if a student knows his/her own learning style and applies it to the learning - teaching process, s/he will learn both more easily and more rapidly and there is a high degree of probability that $\mathrm{s} / \mathrm{he}$ will be successful in the learning process.

\subsection{The Significance of the Study}

Present study reveals the views and priorities of students (receiving education in online learning environments) on the environment where they receive their education. The determination of the importance attached by students to the main and the sub-components of an online environment is an indicator of what they pay attention to and which factors they consider particularly important in a quality learning experience. In this process, a comparison of the results obtained by regarding an individual difference like the learning style is another significant point. Learning styles are among the most important of individual differences, and they are mostly innate, though they may go through partial changes later on due to environmental factors. Therefore, it is thought that analyzing student views and their priorities in relation to their learning styles and comparing online environment components may offer a contribution to the literature in the field.

\section{Method}

The aim of this study is to examine the learning styles of students receiving education in online learning environments and to analyze their views on the existing learning environment.

\subsection{Research Problem}

Do the views of students about online learning environments vary according to their individual learning styles? Do individual learning styles have an impact on the determination of student preferences related to the main and the sub-components of the online learning environment?

\subsubsection{Sub-problems}

- What are the views of students with a visual learning style about the main and the sub-components of online learning environments?

- What are the views of students with an auditory learning style about the main and the sub-components of online learning environments?

- What are the views of students with a kinesthetic learning style about the main and the sub-components of online learning environments?

- Do student views about the main and the sub-components of online learning environments vary according to the learning styles of the students? 


\subsection{Research Group}

The research group of the study consists of 3. grade university students taking Distance Education courses who are enrolled in Faculty of Education, Department of Computer Education and Instructional Technology in the academic year 2009-2010, fall semester. 44 students, 14 of whom are females and 30 of whom are males, were included in the present study (32\% females, $68 \%$ males). Of the students that comprised the research group, $41 \%$ had visual learning styles, $34 \%$ had auditory learning styles, and $25 \%$ had kinesthetic learning styles.

\subsection{Data Collection Tools}

Maggie McVay Lynch Learning Style Inventory and a conjoint questionnaire were used for data collection. Linguistic equivalence, validity and reliability studies of the learning style inventory were conducted and the inventory was adapted to Turkish (Dağhan and Akkoyunlu, 2011). Then, a conjoint questionnaire was prepared to determine the views of the students. Finally, the data obtained through conjoint questionnaire and the data obtained through the learning style inventory were associated.

\subsection{Data Analysis}

Conjoint analysis, which is a multivariate statistical technique, was used to analyze the conjoint questionnaire related to student views. Conjoint analysis is a multivariate statistical technique allowing the determination of the reasons for consumer choice of a particular service and the impacts of many of the qualities that make up a service (Dijkstra and Timmermans, 1997). In the present study, students were considered as consumers, and the online learning environment was considered as the service provided or the product marketed.

Used mostly in marketing surveys, the conjoint analysis method requires consumers to determine their preference decisions by taking into account all factors. Conjoint is an abbreviation of the expression "considered jointly" (Erdoğan, 2006), conjoint analysis has begun to be used in studies more frequently in recent years as it provides a collective perspective on all the dimensions and factors of a product or a service, and yields quality results for determining whether a factor is desired enough to give up another factor or which factor is given up if one factor is to be given up.

The dependent variable in the present study is the preference ranking of the students, while the independent variables are the main features of online learning environments and the sub-components belonging to these features (main factors and sub-factors). Since the preference ranking of the students corresponds to the quantitative data, there is no obstacle to the interpretation of these data, but the independent variables of the study are qualitative data. In this study, a dummy variable regression technique was employed in order to interpret these qualitative data. In the dummy variable regression technique, dummy variables as many as one less than the number of sub-factors were determined for each main factor. For instance, two dummy variables, 0 and 1 , were used for the learning materials main factor. That is because the learning materials main factor consists of three different sub-factors, which are visual, auditory and kinesthetic.

In the dummy variable regression technique, the dummy variable takes the value of 1 if the level related to the variable is selected, and takes the value of 0 if it is not selected. Table 1 presents an example of the encoding of each level of three and four-level variables with dummy variables.

Table 1. Example of the encoding of the levels of three and four-level variables with dummy variables

\begin{tabular}{ccccccc}
\hline \multicolumn{2}{c}{ Encoding Belonging to Three-Level Variable } & \multicolumn{5}{c}{ Encoding Belonging to Four-Level Variable } \\
\hline Level & $\mathrm{X} 1$ & $\mathrm{X} 2$ & Level & $\mathrm{Y} 1$ & $\mathrm{Y} 2$ & $\mathrm{Y} 3$ \\
1 & 1 & 0 & 1 & 1 & 0 & 0 \\
2 & 0 & 1 & 2 & 0 & 1 & 0 \\
3 & 0 & 0 & 3 & 0 & 0 & 1 \\
& & & 4 & 0 & 0 & 0 \\
\hline
\end{tabular}

$\mathrm{X} 1$ and $\mathrm{X} 2$ dummy variables belonging to three-level variable, and $\mathrm{Y} 1, \mathrm{Y} 2$ and $\mathrm{Y} 3$ dummy variables belonging to four-level variable were defined. No variable in the $3 \mathrm{rd}$ level in encoding belonging to the three-level variable and no variable in the 4th level in encoding belonging to the four-level variable take the value of 1 . These levels are called "reference levels".

The dummy variable regression model related to ranking scores given to trial combinations in the conjoint 
questionnaire is defined as:

$\mathrm{S}_{1 \mathrm{j}}=\beta_{0}+\beta_{1} \mathrm{X}_{1}+\beta_{2} \mathrm{X}_{2}+\beta_{3} \mathrm{X}_{3}+\ldots \ldots . .+\beta_{\mathrm{q}} \mathrm{X}_{\mathrm{q}}+\varepsilon_{\mathrm{h}}$

(Çamlıdere, 2005).

Since $\mathrm{h}=1,2,3 \ldots \mathrm{q}$ and $\mathrm{j}=1,2,3 \ldots . \mathrm{v}$ (v: the number of trial combinations), the meaning of expressions in the regression model is as follows (Çamlidere, 2005).

$\mathrm{S}_{1 \mathrm{j}}$ : Ranking score given by the $1^{\text {st }}$ respondent for number $\mathrm{j}$ trial combination

$\beta_{\mathrm{h}}$ : Regression coefficients

q: Dummy variable number

$\mathrm{X}_{\mathrm{h}}$ : Dummy variables defined for level of the variable

$\varepsilon_{\mathrm{h}}$ : Error Term

By means of the dummy variable regression analysis technique, individual utility coefficients belonging to the preference ranking of students are calculated for sub-components of each main factor. In other words, a respondent has as many individual utility coefficients as the number of sub-factors. The utility coefficient belonging to a sub-component refers to the contribution to be made to the total utility if this sub-level is selected. An increase is observed in the expected preference scores when the individual utility coefficients are positive, and a decrease is observed in the expected preference scores when they are negative.

To make any interpretation concerning the main factors, it is necessary to calculate relative importance values. Individual utility coefficients are used while relative importance values are being calculated. The relative importance values indicate the percentage of importance attached by a respondent to the main factors. These values should be primarily interpreted as they form a general perspective on the independent variables of the study.

\subsection{Limitations of the Study}

It should be noted that the findings reported in this study are based on the data collected in one department of a university. Because of this, generalization of the findings is limited. To draw a more generalized conclusion, studies involving a wider range of students, teachers, and schools are needed. Future studies can look into the preferences of students in wide range of samples.

\section{Findings}

\subsection{Findings Related to the Visual Learning Style}

The first sub-problem of the present study is, "What are the views of students with a visual learning style about the main and the sub-components of online learning environments?" According to the conjoint analysis findings, students having a visual learning style adopt the interaction type as the primary main factor $(28.18 \%)$. The interaction type is followed by the employed technology characteristic (23.15\%), flexibility (3.09\%), type of learning materials $(13.31 \%)$ and mode of communication $(6.35 \%)$. For visual learning style students, the most unimportant main factor was determined as the technical support (5.90\%).

Analysis of the interaction type main factor showed that the students with visual learning style attached great importance to the student - administrator interaction, with a utility coefficient of 2.0167. This interaction type was followed by student - content interaction, with a utility coefficient of 0.4500 , and student - student interaction, with a utility coefficient of -0.3611 . For visual learning style students, the most unimportant sub-factor of the interaction type main factor was found to be the student - environment interaction, with a benefit coefficient of -2.1056 .

Analysis of the employed technology characteristic main factor found that the students with visual learning style attached importance to online whiteboard applications the most, with a utility coefficient of 1.0889 . This technology characteristic was followed by e-mail, with a utility coefficient of 0.5778 , chatting, with a utility coefficient of 0.2778 , and the online environment organizing (blog, wiki), with a utility coefficient of -0.1556 . For visual learning style students, the most unimportant sub-factor of the employed technology characteristic main factor was found to be the learning management system, with a utility coefficient of -1.7889 .

Analysis of flexibility main factor, it showed that the students with visual learning style attached importance to time independency the most, with a utility coefficient of 1.3819 . This mode of flexibility was followed by progressing at one's own speed, with a utility coefficient of 0.7097 and individual working, with a utility 
coefficient of -0.8014 . For visual learning style students, the most unimportant sub-factor of the flexibility main factor was found to be space independency, with a utility coefficient of -1.2903.

Learning materials main factor was analyzed and it was determined that the students with visual learning style primarily preferred visual learning materials, with a utility coefficient of 0.9148 . This sub-factor was respectively followed by auditory learning materials, with a utility coefficient of 0.1315 and kinesthetic learning materials, with a utility coefficient of -1.0463 .

Mode of communication main factor which had a relative importance percentage of $6.35 \%$ was analyzed. It can be stated that synchronous communication, having a utility coefficient of 0.3426 , was preferred to asynchronous communication, having a utility coefficient of -0.3426 .

Analysis of technical support main factor, which was considered by visual learning students as the least important within the general model, with a relative importance level of $5.90 \%$ showed that the non-existence of the technical support sub-factor, with a utility coefficient of 0.4074 was found to be more dominant than the existence of technical support, with a utility coefficient of 0.2037 . Since the expected value of this main factor was considered with the existence of technical support, the independent variable was defined as "linear more" at the beginning of the study. However, 10 of 18 visual learning style students had to give negative answers to this main factor. The reason is that the technical support main factor was considered less important than the other main factors, and preference ranking was performed by primarily considering the other main factors and their sub-components. For example, for a visual learning style student, student - the administrator interaction type or the flexibility of the environment in the form of time independency was considered more important than the existence of technical support in the online learning environment.

\subsubsection{Model Writing Related to Visual Learning Style and the Results of Card Scores}

Since utility coefficients of all the sub-factors of the main factors were calculated in accordance with the preferences of students with a visual learning style, the score values of each card should be determined. In this way, the cards that are the suitable and not suitable to the individual preferences of students with a visual learning style can be determined. For that, firstly, a model should be established, utility coefficients (utility values) should be located in their positions in the model, the score values belonging to each card should be calculated, and preference ranking should be performed. The model established for preference ranking to be performed is as follows:

Utility=Constant $+\left(\beta_{1}\right)$ Type of Learning Materials $+\left(\beta_{2}\right)$ Technical Support $+\left(\beta_{3}\right)$ Mode of Communication + $\left(\beta_{4}\right)$ Employed Technology Characteristic $+\left(\beta_{5}\right)$ Flexibility $+\left(\beta_{6}\right)$ Interaction Type

The constant coefficient of the established model was found to be 12.2329. Utility coefficients were located in their positions in the model and the score values were calculated for each card. They are shown in table 2 in descending order.

Table 2. Card numbers related to visual learning style and score results

\begin{tabular}{cccccccc}
\hline $\begin{array}{c}\text { Card } \\
\text { No }\end{array}$ & Card Score & $\begin{array}{c}\text { Card } \\
\text { No }\end{array}$ & Card Score & $\begin{array}{c}\text { Card } \\
\text { No }\end{array}$ & Card Score & $\begin{array}{c}\text { Card } \\
\text { No }\end{array}$ & Card Score \\
\hline 17 & 17.1407 & 11 & 13.5481 & 18 & 12.9259 & 6 & 12.0407 \\
16 & 16.5167 & 15 & 13.4796 & 5 & 12.6463 & 3 & 11.1630 \\
14 & 16.1333 & 13 & 13.1704 & 7 & 12.4463 & 21 & 10.9407 \\
24 & 15.4093 & 12 & 13.1370 & 19 & 12.3759 & 1 & 10.6741 \\
8 & 15.2148 & 23 & 13.0907 & 25 & 12.3463 & 20 & 10.5759 \\
22 & 14.3352 & 4 & 13.0648 & 9 & 12.3278 & 2 & 6.5556 \\
10 & 13.7407 & & & & & & \\
\hline
\end{tabular}

Analysis of table 2 shows that the card that is most appropriate for student preferences is card no. 17. This is a card associated with an environment which contains visual learning materials and in which online environment organizing (blog, wiki, etc.) technologies are used, synchronous communication is established, there is no 
technical support, learners can access the learning environment on the basis of a time independency principle, and student - administration is provided. The card that is not suitable to the preferences of students was determined to be card no. 2. This is a card associated with an environment which contains kinesthetic learning materials and in which learning management system (Moodle, Blackboard, etc.) technologies are used, a synchronous communication is established, there is no technical support, the individual work of learners is featured, and student - environment interaction is provided.

3.1.2 Significance Tests of the Model Established Concerning Visual Learning Style and the Interpretation of the Simulation Cards

The results of both the Pearson R and Kendall Tau statistics show that there is a high relationship between the independent variables in the established model at a significance level of 0.05 and the variables are suitable for expressing the established model (Pearson $\mathrm{R}=.930$, Kendall Tau $=.772, \mathrm{p}<.05$ ).

Four simulation cards were prepared within the scope of the present study. These cards are represented in table 3.

Table 3. Simulation cards prepared within the scope of the present study

\begin{tabular}{|c|c|c|c|c|c|c|}
\hline $\begin{array}{l}\text { Card } \\
\text { No }\end{array}$ & $\begin{array}{l}\text { Type of } \\
\text { Learning } \\
\text { Materials }\end{array}$ & $\begin{array}{c}\text { Employed } \\
\text { Technology } \\
\text { Characteristic }\end{array}$ & $\begin{array}{c}\text { Mode of } \\
\text { Communication }\end{array}$ & $\begin{array}{c}\text { Technical } \\
\text { Support }\end{array}$ & Flexibility & $\begin{array}{l}\text { Interaction } \\
\text { Type }\end{array}$ \\
\hline 1 & Visual & $\begin{array}{c}\text { Learning } \\
\text { Management } \\
\text { System }\end{array}$ & Asynchronous & Available & $\begin{array}{c}\text { Progressing at } \\
\text { One's Own } \\
\text { Speed }\end{array}$ & $\begin{array}{l}\text { Student - } \\
\text { Student }\end{array}$ \\
\hline 2 & Kinesthetic & $\begin{array}{c}\text { Online } \\
\text { Environment } \\
\text { Organizing }\end{array}$ & Asynchronous & Available & $\begin{array}{l}\text { Individual } \\
\text { Working }\end{array}$ & $\begin{array}{c}\text { Student - } \\
\text { Administrator }\end{array}$ \\
\hline 3 & Auditory & Chatting & Synchronous & Available & $\begin{array}{c}\text { Progressing at } \\
\text { One's Own } \\
\text { Speed }\end{array}$ & $\begin{array}{l}\text { Student - } \\
\text { Content }\end{array}$ \\
\hline 4 & Visual & $\begin{array}{c}\text { Online } \\
\text { Environment } \\
\text { Organizing }\end{array}$ & Asynchronous & Available & $\begin{array}{c}\text { Time } \\
\text { Independent }\end{array}$ & $\begin{array}{l}\text { Student - } \\
\text { Content }\end{array}$ \\
\hline
\end{tabular}

According to the answers given by students having a visual learning style, the result of the 1st simulation card was found to be 11.6; that of the 2nd simulation card was found to be 12.1; that of the 3rd simulation card was found to be 14.3; and that of the 4th simulation card was found to be 14.7. While students preferred the 4th simulation card in the 1st rank with the highest score, they preferred the 1st simulation card in the 4th rank with the lowest score.

The Max. Utility, Bradley - Terry Luce and Logit coefficients related to the four simulation cards were obtained in percentages. They are shown in table 4 .

Table 4. Max. Utility, BTL and Logit percentages related to simulation cards (for visual learning style)

\begin{tabular}{cccc}
\hline Card No & Max. Utility (\%) & BTL (\%) & Logit (\%) \\
\hline 1 & 27.78 & 24.11 & 24.72 \\
2 & 5.56 & 22.13 & 13.25 \\
3 & 22.22 & 27.69 & 25.78 \\
4 & 44.44 & 26.06 & 36.25 \\
\hline
\end{tabular}


In table 4, Max. Utility, BTL (Bradley Terry - Luce) and Logit coefficients related to four possible combinations used for simulation purposes are expressed in percentages. Considering the determined percentages, it is observed that simulation card no. 4 is the card combination that is most suitable for the preferences of students having a visual learning style. In Bradley Terry - Luce percentages, the score of the simulation card no. 3 is slightly higher than that of card no. 4. However, this difference is very small, and it can be stated that card no. 4 is closer to student preferences taking into account max. utility and logit percentages.

\subsection{Findings Related to the Auditory Learning Style}

The second sub-problem of the present study is, "What are the views of students with an auditory learning style about the main and the sub-components of online learning environments?" According to the conjoint analysis findings, students with an auditory learning style consider interaction type as the primary important factor $(23.87 \%)$. Interaction type is followed by the employed technology characteristic $(22.90 \%)$, flexibility $(20.05 \%)$, the type of learning materials $(18.15 \%)$ and technical support $(7.86 \%)$. For auditory learning style students, the most unimportant factor was determined as the mode of communication (7.1\%).

Analysis of the interaction type main factor showed that the auditory learning style students attached importance to student-student interaction the most, with a utility coefficient of 0.6833 . This interaction type was followed by student - content interaction, with a utility coefficient of 0.2167 , and student - administrator interaction, with a utility coefficient of -0.3433 . For auditory learning style students, the least important sub-factor of interaction type main factor was found to be the student - environment interaction, with a utility coefficient of -0.5567 .

Employed technology characteristic main factor was analyzed and it was observed that the auditory learning style students attached importance to the online whiteboard applications the most, with a utility coefficient of 1.3600. This technology characteristic was followed by chatting, with a utility coefficient of 0.8267 , learning management system, with a utility coefficient of 0.4933 , and online environment organizing (blog, wiki, etc.), with a utility coefficient of -1.2533 . For auditory learning style students, e-mail was found to be the most unimportant sub-factor of the employed technology characteristic main factor, with a utility coefficient of -1.4267 .

Analysis of the flexibility main factor showed that auditory learning style students attached importance to time independency the most, with a utility coefficient of 0.9083 . This mode of flexibility was followed by progressing at one's own speed, with a utility coefficient of 0.2217 and space independency, with a utility coefficient of 0.1550 . For auditory learning style students, the least important sub-factor of flexibility main factor was found to be individual working, with a utility coefficient of -1.2850 .

Type of learning materials main factor was analyzed and it was determined that auditory learning style students primarily preferred auditory learning materials, with a utility coefficient of 0.8178 . This sub-factor was respectively followed by kinesthetic learning materials, with a utility coefficient of 0.1111 and visual learning materials, with a utility coefficient of -0.9289 .

Technical support main factor with a relative importance level of $7.86 \%$ was analyzed and it was found that the non-existence of technical support sub-factor, with a utility coefficient of 2.1111 was preferred to the existence of the technical support sub-factor, with a utility coefficient of 1.0556. The expected value of this main factor suggests the existence of technical support. However, 5 of the 15 auditory learning style students gave negative answers to this main factor. As in the visual learning style, the reason is that the technical support main factor was considered less important than the other main factors, and the preference ordering was primarily performed by taking into account other main factors and their sub-components. For an auditory learning style student, student - student interaction type or the flexibility of the environment in the form of time independency was considered more important than the existence of technical support in the online learning environment.

Mode of communication that was considered the least important within the general model by the auditory learning style students, with a relative importance percentage of $7.17 \%$ was analyzed and it was observed that synchronous communication, with a utility coefficient 0.1500 , was preferred to asynchronous communication, with a utility coefficient of -0.1500 .

\subsubsection{Model Writing Related to the Auditory Learning Style and the Results of the Card Scores}

Since utility coefficients associated with all the sub-factors of the main factors were calculated in accordance with the preferences of students with auditory learning style, the score values of each card should be determined. In this way, the cards that are suitable and not suitable to the individual preferences of students having an auditory learning style can be determined. For that, firstly, a model should be established, the utility coefficients (utility values) should be located in their positions in the model, the score values belonging to each card should 
be calculated, and preference ranking should be performed. The model established in order of preference ranking to be performed is the same as the model established for students with a visual learning style as follows:

Utility=Coefficient $+\left(\beta_{1}\right)$ Type of Learning Materials $+\left(\beta_{2}\right)$ Technical Support $+\left(\beta_{3}\right)$ Mode of Communication + $\left(\beta_{4}\right)$ Employed Technology Characteristic $+\left(\beta_{5}\right)$ Flexibility $+\left(\beta_{6}\right)$ Interaction Type

The constant coefficient of the established model was found to be 11.1961 . The utility coefficients were put in their positions in the model and the score values were calculated for each card. They are shown in table 5 in descending order.

Table 5. Card numbers related to auditory learning style and the score results

\begin{tabular}{cccccccc}
\hline Card No & $\begin{array}{c}\text { Card } \\
\text { Score }\end{array}$ & Card No & $\begin{array}{c}\text { Card } \\
\text { Score }\end{array}$ & Card No & $\begin{array}{c}\text { Card } \\
\text { Score }\end{array}$ & Card No & $\begin{array}{c}\text { Card } \\
\text { Score }\end{array}$ \\
\hline 25 & 16.3600 & 6 & 13.6867 & 21 & 12.6867 & 17 & 11.8400 \\
10 & 16.0067 & 18 & 13.5578 & 9 & 12.4533 & 1 & 11.3311 \\
15 & 15.9867 & 7 & 13.3711 & 4 & 12.4044 & 12 & 10.7244 \\
22 & 14.8711 & 23 & 13.2578 & 5 & 12.3778 & 16 & 10.6800 \\
13 & 14.7778 & 3 & 13.2244 & 2 & 11.9200 & 11 & 10.3978 \\
14 & 14.7133 & 8 & 12.9511 & 20 & 11.8978 & 19 & 9.6178 \\
24 & 13.9044 & & & & & & \\
\hline
\end{tabular}

Analysis of table 5 shows that card no. 25 is the most suitable card for student preferences. This is a card associated with an environment which contains auditory learning materials and in which learning management system (Moodle, Blackboard, etc.) technologies are used, a synchronous communication is established, there is no technical support, learners can reach the environment on the basis of a time independency principle, and student - student interaction is provided. The card which is not suitable for the preferences of students was found to be card no. 19. This is a card associated with an environment that contains visual learning materials and in which online environment organizing (blog, wiki, etc.) technologies are used, synchronous communication is established, there is a technical support, students are provided with an opportunity to work together, and student - student interaction is provided.

3.2.2 Significance Tests of the Model Established Concerning Auditory Learning Style and the Interpretation of Simulation Cards

The results of both Pearson $\mathrm{R}$ and Kendall Tau statistics show that there is a high relationship between the independent variables in the established model, this relationship is significant at a level of significance of 0.05 , and the variables are suitable for expressing the established model (Pearson $\mathrm{R}=.729$, Kendall $\mathrm{Tau}=.459, \mathrm{p}<.05$ ).

Four simulation cards prepared within the scope of the study were tested among students with an auditory learning style and the findings obtained were interpreted. According to the answers given by students with an auditory learning style, the result of the 1st simulation card was found to be 12.6, that of the 2nd simulation card was found to be 9.3 , that of the 3 rd simulation card was found to be 14.5 , and that of the 4 th simulation card was found to be 11.0. While students preferred the 3rd simulation card in the 1st rank with the highest score value, they preferred the 2nd simulation card in the 4th rank with the lowest simulation card.

Max. Utility, Bradley - Terry Luce and Logit coefficients related to four simulation cards were obtained in percentages. They are shown in table 6 .

Table 6. Max. Utility, BTL and Logit percentages related to simulation cards (for auditory learning style)

\begin{tabular}{cccc}
\hline Card No & Max. Utility (\%) & BTL (\%) & Logit (\%) \\
\hline 1 & 13.33 & 26.53 & 18.73 \\
2 & 20.00 & 19.33 & 17.05 \\
3 & 60.00 & 30.61 & 52.88 \\
4 & 6.67 & 23.53 & 11.35 \\
\hline
\end{tabular}

In table 6, Max. Utility, BTL (Bradley Terry - Luce) and Logit coefficients related to four possible combinations used for simulation purposes were expressed in percentages. Upon examining determined percentages, it was observed that simulation card no. 3 was the card combination that was the most suitable for the preferences of 
students with an auditory learning style. In all three methods, the value of the simulation card no. 3 was found to be the highest.

\subsection{Findings Related to the Kinesthetic Learning Style}

The third sub-problem of the present study is "What are views of students with a kinesthetic learning style about the main and the sub-components of online learning environments?" According to conjoint analysis findings, students with a kinesthetic learning style attached importance to the employed technology characteristic as the primary main factor $(31.49 \%)$. The employed technology characteristic is followed by flexibility $(21.46 \%)$, mode of communication (18.54 \%), type of learning materials $(11.98 \%)$, and technical support $(9.35 \%)$. For kinesthetic learning style students, the least important factor was determined to be the mode of communication $(7.18 \%)$.

Employed technology characteristic main factor was analyzed and it was observed that kinesthetic learning students attached importance to the online environment organizing applications the most, with a utility coefficient of 1.3636. This technology characteristic is followed by the online whiteboard applications, with a utility coefficient of 0.1818 , learning management systems, with a utility coefficient of -0.0364 , and chatting, with a utility coefficient of -0.2182 . For kinesthetic learning students, the most unimportant sub-factor of the employed technology characteristic main factor was found to be e-mail, with a utility coefficient of -1.2909.

Flexibility main factor was analyzed and it was observed that kinesthetic learning students attached the importance to individual working the most, with a utility coefficient of 0.8091 . This mode of flexibility was followed by space independency, with a utility coefficient of -0.0091 , and time independency, with a utility coefficient of -0.0455 . For kinesthetic learning students, the least important factor sub-factor of the flexibility main factor was found to be progressing at one's own speed, with a utility coefficient of -0.7545 .

Interaction type main factor was analyzed and it was observed that the kinesthetic learning students attached importance to the student - environment interaction the most, with a utility coefficient of 1.6523 . This interaction type was followed by the student - administrator interaction, with a utility coefficient of 0.2159 and student - student interaction, with a utility coefficient of -0.4659 . For the kinesthetic learning students, the most unimportant sub-factor of the interaction type main factor was found to be the student - content interaction, with a utility coefficient of -1.4023 .

Type of learning materials main factor was analyzed and it was determined that the kinesthetic learning students primarily preferred kinesthetic learning materials, with a utility coefficient of 0.8485 . This sub-factor was respectively followed by visual learning materials, with a utility coefficient of 0.0394 and auditory learning materials, with a utility coefficient of -0.8879 .

Technical support main factor, with a relative importance percentage of $9.35 \%$ was analyzed and it can be stated that the existence of the technical support sub-factor, with a utility coefficient of -0.5303 was preferred to the non-existence of the technical support sub-factor, having a utility coefficient of -1.0606 . The expected value of this main factor suggested the existence of technical support. The result also corresponds to the expected value of the technical support main factor. However, 5 of the 11 kinesthetic learning style students gave negative answers to this main factor. As in the visual and auditory learning styles, the reason is that the technical support main factor was considered more unimportant than other main factors, and the preference ordering was primarily performed considering other main factors and their sub-components. For a kinesthetic learning style student, the student - environment interaction type or the flexibility of the environment in the form of allowing individual working was considered more important than the existence of technical support in the online learning environment.

Mode of communication main factor which is considered the least important within the general model by kinesthetic learning style students with a relative importance percentage of $7.18 \%$ was analyzed and it was found that asynchronous communication, with a utility coefficient of 0.1818 was preferred more than synchronous communication, with a utility coefficient of -0.1818 .

\subsubsection{Model Writing Related to the Kinesthetic Learning Style and the Results of the Card Scores}

Since the utility coefficients associated with all the sub-factors of the main factors were calculated in accordance with the preferences of students with a kinesthetic learning style, the score values of each card should be determined. In this way, the cards that are suitable and not suitable to the individual preferences of students having a kinesthetic learning style can be determined. For that, firstly, a model should be established, utility coefficients (utility values) should be located in their positions in the model, the score values belonging to each card should be calculated, and preference ranking should be performed. The model established in order for 
preference ranking to be performed is the same as the models established for students with visual and auditory learning styles as follows:

Utility=Constant $+\left(\beta_{1}\right)$ Type of Leaning Materials $+\left(\beta_{2}\right)$ Technical Support $+\left(\beta_{3}\right)$ Mode of Communication + $\left(\beta_{4}\right)$ Employed Technology Characteristic $+\left(\beta_{5}\right)$ Flexibility $+\left(\beta_{6}\right)$ Interaction Type

The constant coefficient of the established model was found to be 14.0508. The utility coefficients were located in their positions in the model and the score values were calculated for each card. They are shown in table 7 in descending order.

Table 7. Card numbers related to kinesthetic learning style and score results

\begin{tabular}{cccccccc}
\hline Card No & $\begin{array}{c}\text { Card } \\
\text { Score }\end{array}$ & Card No & $\begin{array}{c}\text { Card } \\
\text { Score }\end{array}$ & Card No & $\begin{array}{c}\text { Card } \\
\text { Score }\end{array}$ & Card No & $\begin{array}{c}\text { Card } \\
\text { Score }\end{array}$ \\
\hline 2 & 16.4455 & 11 & 13.6939 & 13 & 13.1485 & 25 & 11.3727 \\
19 & 15.0848 & 23 & 13.6667 & 3 & 12.9848 & 4 & 11.1848 \\
1 & 15.0758 & 8 & 13.6576 & 18 & 12.8303 & 22 & 11.1485 \\
20 & 14.8030 & 21 & 13.6091 & 5 & 12.7485 & 12 & 10.5667 \\
17 & 14.3818 & 7 & 13.4485 & 14 & 11.9455 & 10 & 10.4818 \\
24 & 14.1394 & 9 & 13.3364 & 16 & 11.3818 & 6 & 10.1545 \\
15 & 13.7091 & & & & & & \\
\hline
\end{tabular}

It is observed from table 7 that the card which is the most suitable for the preferences of the students is card no. 2 . This is a card associated with an environment which contains kinesthetic learning materials and in which learning management system (Moodle, Blackboard, etc.) technologies are used, an asynchronous communication is established, there is no technical support, students are provided with an individual working opportunity in the learning environment, and student - environment interaction is provided. The card which is not suitable to the preferences of the students was found to be card no. 6. This is a card associated with an environment which contains auditory learning materials and in which e-mail technology is used, synchronous communication is established, there is no technical support, students can reach the learning environment independently of space, and student - student interaction is provided.

3.3.2 Significance Tests of the Model Established Concerning Kinesthetic Learning Style and the Interpretation of the Simulation Cards

The results of both the Pearson $\mathrm{R}$ and Kendall Tau statistics show that there is a high relationship between the independent variables in the established model, this relationship is significant at a level of significance of 0.05 , and the variables are suitable for expressing the established model (Pearson $\mathrm{R}=.779$, Kendall $\mathrm{Tau}=.595, \mathrm{p}<.05$ ).

Four simulation cards prepared within the scope of the study were tested among students with a kinesthetic learning style and the obtained findings were interpreted. According to the answers given by students with a kinesthetic learning style, the result of the 1st simulation card was found to be 12.5; that of the 2nd simulation card was found to be 16.9; that of the 3rd simulation card was found to be 10.1; and that of the 4th simulation card was found to be 13.7. While students preferred the 2 nd simulation card in the 1st rank with the highest score value, they preferred the 3 rd simulation card in the 4th rank with the lowest simulation card.

Max. Utility, Bradley - Terry Luce and Logit coefficients related to four simulation cards were obtained in percentages. They are shown in table 8 .

Table 8. Max. Utility, BTL and Logit percentages related to simulation cards (for kinesthetic learning style)

\begin{tabular}{cccc}
\hline Card No & Max. Utility (\%) & BTL (\%) & Logit (\%) \\
\hline 1 & 9.09 & 21.30 & 14.52 \\
2 & 45.45 & 32.51 & 47.27 \\
3 & 27.27 & 19.04 & 18.85 \\
4 & 18.18 & 27.16 & 19.36 \\
\hline
\end{tabular}


In table 8, Max. Utility, BTL (Bradley Terry - Luce) and Logit coefficients related to 4 possible combinations used for simulation purposes are expressed in percentages. Upon examining the determined percentages, it is observed that simulation card no. 2 was the most suitable card combination for the preferences of students with a kinesthetic learning style. In all three methods, the value of simulation card no. 2 was found to be the highest.

\subsection{Research Findings Related to the Research Group}

The 4th sub-problem of the present study is, "Do student views about the main and the sub-components of online learning environments vary according to the learning styles of the students?". The hypotheses established to receive an answer to this sub-problem are as follows:

$\mathrm{H}_{0}$ : Student views about the environment do not vary by their learning styles.

$\mathrm{H}_{1}$ : Student views about the environment vary by their learning styles.

According to the conjoint analysis findings, students in the online environment attached great importance to the employed technology characteristic as the primary main factor $(25.15 \%)$. The employed technology characteristic is followed by the interaction type (24.30\%), flexibility (21.6 5\%), type of learning materials $(14.63 \%)$ and technical support $(7.43 \%)$. For all of the students in the environment, the least important main factor was determined to be the mode of communication (6.84 \%).

Employed technology characteristic main factor was analyzed and it was observed that students attached importance to whiteboard applications the most, with a utility coefficient of 0.9545 . This technology characteristic was followed by chatting, with a utility coefficient of 0.3409 and the online learning organizing application, with a utility coefficient of -0.1500 . For students in the online learning environment, the least important sub-factors of the employed technology characteristic main factor were found to be e-mail and learning management systems, with a utility coefficient of -0.5727 .

Interaction type main factor was analyzed and it was observed that students attached importance to student administrator interaction the most, with a utility coefficient of 0.7619 . This interaction type was followed by student - student interaction, with a utility coefficient of -0.0312 and student - content interaction, with a utility coefficient of -0.00926 . For students, the most unimportant sub-factor of the interaction type main factor was found to be student - environment interaction, with a utility coefficient of -0.6381 .

Flexibility main factor was analyzed and it was observed that students attached importance to the time independency principle, with a utility coefficient of 0.8636 . This mode of flexibility was followed by progressing at one's own speed, with a utility coefficient of 0.1773 , and space independency, with a utility coefficient of -0.4773 . For all of the students in the research group, the least important sub-factor of the flexibility main factor was found to be individual working, with a utility coefficient of -0.5636 . Students did not attach much importance to the feature of online learning environments that allowed for individual working.

Type of learning materials main factor was analyzed and it was determined that students primarily preferred auditory learning materials, with a utility coefficient of 0.1106 . This sub-factor was respectively followed by visual learning materials, with a utility coefficient of 0.0674 and kinesthetic learning materials, with a utility coefficient of -0.1780 .

Technical support main factor with a relative importance percentage of $7.43 \%$ was analyzed and it can be stated that the non-existence of the technical support sub-factor, with a utility coefficient of 0.6212 was preferred to the existence of the technical support sub-factor, with a utility coefficient of 0.3106 . The expected value of this main factor suggested the existence of technical support; however 20 of 44 students in the research group gave negative answers to this main factor. As in the visual, auditory and kinesthetic learning styles, the reason is that the technical support main factor was considered more unimportant than the other main factors, and the preference ranking was primarily performed considering other main factors and their sub-components. The students in the research group gave a greater importance to student - administrator type interaction or to the flexibility of the environment in such a way to allow for progression at one's own speed than the existence of technical support in the online learning environment.

Mode of communication main factor which was considered the least important within the general model by students in the research group, with a relative importance percentage of $6.84 \%$ was analyzed and it was realized that synchronous communication, with a utility coefficient of 0.1458 was preferred to asynchronous communication, with a utility coefficient of -0.1458 . 


\subsubsection{Model Writing Related to All Students in the Research Group and the Results of the Card Scores}

Since the utility coefficients associated with all the sub-factors of the main factors are calculated in accordance with the preferences of the students in the research group, the score values of each card should be determined. In this way, the cards that are the suitable and not suitable to the individual preferences of students can be determined. For that, firstly, a model should be established, utility coefficients should be located in their positions in the model, the score values belonging to each card should be calculated, and preference ranking should be performed. The model established in order for preference ranking to be performed is the same as the model established for students having visual, auditory and kinesthetic learning styles as follows:

Utility=Constant $+\left(\beta_{1}\right)$ Type of Learning Materials $+\left(\beta_{2}\right)$ Technical Support $+\left(\beta_{3}\right)$ Mode of Communication + $\left(\beta_{4}\right)$ Employed Technology Characteristic $+\left(\beta_{5}\right)$ Flexibility $+\left(\beta_{6}\right)$ Interaction Type

The constant coefficient of the established model was found to be 12.3339 . The utility coefficients were located in their positions in the model and the score values were calculated for each card. They are shown in table 9 in descending order.

Table 9. Card Numbers Related to All Students in the Research Group and Score Results

\begin{tabular}{cccccccc}
\hline Card No & Card Score & Card No & Card Score & Card No & Card Score & Card No & Card Score \\
\hline 17 & 14.6439 & 10 & 13.6985 & 9 & 12.6227 & 6 & 12.1303 \\
14 & 14.6023 & 25 & 13.4712 & 5 & 12.5803 & 19 & 12.1129 \\
24 & 14.5788 & 23 & 13.2917 & 11 & 12.5106 & 20 & 12.0833 \\
15 & 14.3917 & 16 & 13.2432 & 4 & 12.3697 & 1 & 11.9985 \\
8 & 14.0538 & 18 & 13.1174 & 3 & 12.3212 & 12 & 11.6720 \\
22 & 13.7212 & 7 & 13.0121 & 21 & 12.2030 & 2 & 10.8568 \\
13 & 13.7129 & & & & & & \\
\hline
\end{tabular}

It is understood from table 9 that the card which is most appropriate for the preferences of students is card no. 17. This is a card associated with an environment which contains visual learning materials and in which the online environment organizing (blog, wiki, etc.) is used, synchronous communication is established, there is no technical support, learners can reach learning environments independently from time, and student - administrator interaction is provided. The card which is not suitable to the preferences of the students was found to be card no. 2. This is a card associated with an environment which contains kinesthetic learning materials and in which learning management system technology is used, asynchronous communication is established, there is no technical support, students are provided with an individual working opportunity, and the student - environment interaction is provided.

3.4.2 Significance Tests of the Model Established Concerning All Students in the Research Group and the Interpretation of the Simulation Cards

The results of both the Pearson $\mathrm{R}$ and Kendall Tau statistics show that there is a high relationship between the independent variables in the established model, this relationship is significant at a level of significance of 0.05 , and the variables are suitable for expressing the established model (Pearson $\mathrm{R}=.828$, Kendall $\mathrm{Tau}=.620, \mathrm{p}<.05$ ).

Four simulation cards prepared within the scope of the present study were tested for all students included in the study, and the obtained findings were interpreted. According to the answers given by students, the result of the 1st simulation card was found to be 12.1; that of the 2nd simulation card was found to be 12.4 ; that of the 3 rd simulation card was found to be 13.3; and that of the 4th simulation card was found to be 13.2. While the students preferred the 3rd simulation card in the first rank with the highest score value, they preferred the 1st simulation card in the 4th rank with the lowest score value.

Max. Utility, Bradley - Terry Luce and Logit coefficients related to the four simulation cards were obtained in percentages. They are shown in table 10. 
Table 10. Max. Utility, BTL and Logit Percentages Related to Simulation Cards (For All Students in the Research Group)

\begin{tabular}{cccc}
\hline Card No & Max. Utility (\%) & BTL (\%) & Logit (\%) \\
\hline 1 & 18.18 & 24.38 & 20.29 \\
2 & 20.45 & 23.38 & 22.11 \\
3 & 36.36 & 26.86 & 34.17 \\
4 & 25.00 & 25.38 & 23.43 \\
\hline
\end{tabular}

In table 10, Max. Utility, BTL (Bradley Terry - Luce) and Logit coefficients related to four possible combinations used for simulation purposes were expressed in percentages. According to the analysis of the determined percentages, simulation card no. 3 is the card combination most suitable for the preferences of all the students included in the present study. In all three methods, the value of simulation card no. 3 was found to be the highest.

Individual analyses performed concerning the learning styles of students receiving education in online learning environments and the analyses performed on the entire research group were analyzed and it was concluded that students' views varied according to their learning styles. Accordingly, the $\mathrm{H}_{0}$ hypothesis was rejected, and the $\mathrm{H}_{1}$ hypothesis was accepted. For example, while the online learning environment main factor which was considered the most important by students having visual learning styles and students having auditory learning styles was the mode of communication, the most important main factor considered the most important by kinesthetic learning students was found to be employed technology characteristic. As a different example, considering the mode of communication main factor, visual learning style students attached more importance to student - administrator interaction, auditory learning style students attached more importance to student - student interaction, and kinesthetic learning style students attached more importance to student - environment interaction.

Considering the learning styles of students receiving education in online learning styles, another proof of the difference in different views about the environment is the variation in score values which were calculated for the cards in the conjoint questionnaire. For example, while the conjoint card which most resembled the preferences of the visual and auditory learning style students was card no. 25, the conjoint card most appropriate for the preferences of kinesthetic learning style students was card no. 2. Moreover, while the conjoint card which most resembled the preferences of kinesthetic style learning students was card no. 2, the conjoint card which is not suitable to the preferences of visually learning style students was also card no. 2. In terms of the preferences of the conjoint card no. 2, there is a great difference between the visual and the kinesthetic style learning students.

In addition, considering Bradley Terry - Luce, Logit and Max. Utility percentages, the simulation card results related to each learning style, were also found to be different. While the simulation card closest to the preferences of the visual learning style students was the simulation combination no. 4, the simulation card closest to the preferences of the auditory style learning students was the simulation combination no. 3 , and the simulation card closest to the preferences of kinesthetic learning style students was the simulation combination no. 2. The variation in the simulation card preferences according to each learning style is a clear indicator of the fact that students views about the online learning environment vary according to their learning styles. At the end of the 4th sub-problem of the present study, the $\mathrm{H}_{0}$ hypothesis (null hypothesis) was rejected, and the $\mathrm{H}_{1}$ hypothesis (alternative hypothesis) was accepted. In other words, there is a significant difference between the views of students receiving education in online learning environments about the environment they are in and their learning styles.

\section{Conclusion and Discussion}

In this study, an attempt was made to determine the learning styles of students receiving education in online learning environments and their preferences concerning online environments. In order to determine the learning styles of the students, Maggie McVay Lynch Learning Style Inventory was used. A three-factor scale was administered to the research group, and the learning styles of students were determined. A conjoint analysis was prepared to detect the preferences of the students concerning certain components of the online learning environments and the questionnaire results were examined through conjoint analysis. A prepared conjoint questionnaire was individual administered to each learning style group, determined by means of the learning style inventory and the obtained findings were interpreted. 
Data obtained from both the learning style inventory and conjoint analysis was analyzed and it was observed that the students in online learning environments attached importance to the employed technology characteristic the most. The factor related to the employed technology characteristic was followed by factors providing interactions and flexibility in online learning environments respectively.

Considering the entire research group, it was concluded that students in the online learning environments attached great importance to the student - administrator interaction. Students considered this interaction type more important than other interaction types. An online learning environment in which there was an administrator who gave timely, effective and objective feedback to students was considered more important than even the interaction between students. The fact that this interaction type was considered very important by students in online learning environments corresponds to studies conducted on this topic (Özçınar and Öztürk, 2008; Mupinga, Nora and Yaw, 2006; Farahani, 2003). In a study carried out by Soo and Bonk (1998), it was found that student - student interaction was the most important interaction type. This interaction type was followed by the student - administrator interaction type with a value very close to the importance level of this interaction type. Soo and Bonk (1998) stressed the necessity for the existence of an administrator or a teacher in online learning environments though student-centered learning is being carried out.

Separate analysis of the student groups with all three the above-mentioned learning styles showed that there was a great correlation between the learning styles of online students and the learning materials preferred by them. While students having visual learning styles preferred visual learning materials, students having auditory learning styles preferred auditory learning materials, and students having kinesthetic learning styles preferred kinesthetic learning materials. This result was found to be consistent with the expected value of learning style and learning material preference. A study carried out at The National Centre for Vocational Education Research in Australia also found results supporting this finding (NCVER, 2002).

Students in an online learning environment did not consider the technical support factor as very important. For that reason, opposite answers were received in all three learning styles. There were many sub-factors which were more important for students than the existence or non-existence of technical support in the environment. Since students performed ranking by prioritizing these sub-factors, certain inconsistencies emerged between the expected value of the technical support factor and the results obtained. Accordingly, opposite answers were encountered. For example, visual learning students attached more importance to the fact that a student administrator interaction is provided in the environment, students can reach the learning environment independently of time and space and learning management systems are used as the technology characteristic; and all these are of greater significance compared with the existence of technical support in the online environment.

Students did not attach the necessary importance to the mode of communication factor as the case in technical support factor. Students did not consider it important whether communication in the online learning environment was synchronous or asynchronous. The mode of communication main factor was discretely (categorically) defined before the preparation of the conjoint questionnaire. Accordingly, since the sub-factors of the mode of communication main factor did not have any superiority over one another, no opposite answer was encountered.

Considering the relative importance percentages and preference ordering of the main factors examined within the scope of the present study and the utility coefficients of the sub-factors, it is concluded that student views about the main and the sub-components of online learning environments vary according to the learning styles of students. Some findings that can support this result may be mentioned as follows:

- In online learning environments, students having visual learning styles attached importance to student administrator interaction the most, students having auditory learning styles attached importance to student student interaction the most and students having kinesthetic learning styles attached importance to student environment interaction the most.

- Comparison in terms of the flexibility of online learning environments, it was indicated that students having visual and auditory learning styles considered accessing the environment independently of time more important while students having kinesthetic learning styles attached more importance to the environment that allowed for individual working.

- Based on the analysis of employed technology characteristic, it was concluded that while visual and auditory learning students attached more importance to online whiteboard applications, students having kinesthetic learning styles considered the online environment organizing applications such as a blog or wiki to be more important.

- Based on the analysis of mode of communication, it was concluded that while visual and auditory learning 
students attached more importance to synchronous communication, students having kinesthetic learning styles considered asynchronous communication to be more important.

The reason that lies behind students in online learning environments not attaching importance to the technical support main factor is thought to be the result of the fact that the research group consisted of 3rd grade students studying at the Department of Computer Education and Instructional Technology, and that therefore the students in the research group have high levels of computer awareness and high levels of computer self-competence perceptions. All of the students in the research group had taken online courses previously and they were not unfamiliar with these kinds of environments. When these students encountered a problem in the environment, they were able to find a solution to the problem and accordingly they did not attach the necessary importance to technical support. The literature obtains studies which support this finding. In a study conducted by Dağhan and Seferoğlu (2009), it was concluded that students with high competences in respect of the computer did not consider technical support to be important in distance-education environments. It was reported in another study that, thanks to the importance attached by students to interaction, they could easily solve the problems they might encounter in the environment (Franklin, 2002). The fact that students can interact within a short period, and accordingly they can solve the problem through interaction with one another, leads to the result that the existence or non-existence of technical support in the environment is not considered important.

A similar case can also be argued for the mode of communication main factor. Students in the research group had used both synchronous and asynchronous communication in their previous online course experiences and in practices related to the course in which the present study was carried out. For that reason, students who were not unfamiliar with these modes of communication did not consider the mode of communication main factor important.

Analysis of the preferences of students belonging to each one of the three learning styles, it can be argued that the employed technology characteristic, flexibility and the interaction type are considered important by students in online learning environments. Unlike face-to-face learning environments, learning in online learning environments is more individual. Accordingly, students in online learning environments attach importance to the flexibility main factor including features such as time independency, space independency and individual working. That is because these features directly affect the access of the individual to the environment and his/her achievement in the environment. Kim, Liu and Bonk (2005) concluded that $60 \%$ of students in their research group attached great importance to the flexibility of online learning environments.

It is thought that one of indispensable conditions for the achievement of permanent learning in online learning environments is interaction. In the present study, it was concluded that online students attached great importance to the interaction main factor. It is possible to see studies supporting this finding in the relevant literature (Swan et al, 2000; Farahani, 2003).

\section{Recommendations}

Recommendations for future research in accordance with the findings and results obtained in the present study are below.

\subsection{Recommendations for Research on Online Learning}

- The views of students, whose learning styles were determined in the present study, on some components of online learning environments were determined through conjoint analysis. The opinions of students in online learning environments may be analyzed by means of different assessment instruments and a comparison may be made with determined qualifications through conjoint analysis.

- It may be investigated whether student views on online learning environments vary according to other variables such as gender, information and communication technologies literacy, motivation for and attitudes towards learning, computer self-competence perception, and a sense of community.

- The determination of online learning environments' main factors that are given the highest importance by students may be taken into consideration while designing course content to be provided online and the educational process may be maintained in accordance with the preferences of students.

\subsection{Recommendations Concerning the Research Method}

- If conjoint analysis is administered to larger research groups or samples, results that are closer to the real situation may be obtained in accordance with the law of large numbers. Accordingly, different results may be obtained if these kinds of studies are carried out with larger groups and with different parameters.

- In conjoint analysis, the importance percentages of main factors and the utility coefficients of sub-factors 
may receive different values when the research groups or samples change. For that reason, the present study may be adapted to other courses from different departments carried out via online learning. Through such an application, negative answers to some factors concerning the group profile such as technical support may not be encountered.

- Conjoint analysis is based on the principle that there is a conscious and homogenous research group. In this sense, if groups to which data collection tools will be administered in future studies are homogenous and if it is ensured that the answers given by the participants are genuine, the reliability of future researches will increase.

\section{References}

Ally, M. (2004). Foundations of educational theory for online learning. In T. Anderson, \& F. Elloumi (Eds.), Theory and practice of online learning (pp. 3-31). Athabasca, Canada: Athabasca University.

Ayersman, D. J. (1996). Reviewing the research on hypermedia - based learning. Journal of Research on Computing in Education, 28(4), 500-525.

Biggs, J. (2001). Enhancing learning: A matter of style or approach. In R. J. Sternberg, \& L. F. Zhang, (Eds.), Perspectives on thinking, learning and cognitive styles (pp. 73-102). Mahwah: Lawrence Erlbaum Associates.

Bueno, N. (2005). Learning styles in an online learning environment: Students' dominant learning styles and learning outcomes in an online health education class (Doctoral dissertation). Available from ProQuest Dissertations and Theses database. (UMI No. 3202388)

Çamlıdere, Ö. (2005). Konjoint analizi ve cep telefonu tercihleri üzerine bir uygulama (Unpublished master's thesis). Gazi University, Institute of Science, Ankara.

Dağhan, G., \& Akkoyunlu, B. (2011). Maggie Mcvay Lynch öğrenme stili envanterinin Türkçe’ye uyarlanma çalışması. Hacettepe Üniversitesi Eğitim Fakültesi Dergisi, 40, 117-126.

Dağhan, G., \& Seferoğlu, S. S. (2009, October). Uzaktan eğitimin temel boyutlarına iliş̧kin öğrenenlerin tercihleri: Konjoint analizi örneği. Paper presented at the Eighteenth National Conference on Educational Sciences, İzmir, Turkey.

Dijkstra, J., \& Timmermans, H. J. P. (1997). Exploring the possibilities of conjoint measurement as a decision making tool for virtual wayfinding environments, In L., Yu Tung(Ed.), CAADRIA '97 Proceedings of the Second Conference on Computer Aided Architectural Design Research in Asia (pp. 61-72). Taipei: Hu's Pubishers Inc.

Dunn, R., \& Dunn, K. (1993). Teaching secondary students through their individual learning styles: Practical approaches for grades 7- 12. Boston: Allyn and Bacon.

Dunn, R., Gianitti, M. C., Murray, J. B., Rossi, I., \& Quinn, G. P. (1990). Grouping students for instruction: Effects of learning style on achievement and attitudes. The Journal of Social Psychology, 130(4), 485-494. http://dx.doi.org/10.1080/00224545.1990.9924610

Erdoğan, C. (2006). Tüketicinin otomobil tercihinin konjoint analizi ile belirlenmesi (Unpublished master's thesis). Gazi University Institute of Science, Ankara.

Farahani, G. O. (2003). Existence and importance of online interaction (Unpublished doctoral dissertation). Faculty of The Virginia Polytechnic Institute and State University, Fairfax, Virginia.

Felder, R. M. (1996). Matters of style, ASEE Prism, 6(4), 18-23.

Franklin, T. (2002). The instructional, technical, and psychological perspectives of faculty building online courses in cohort settings. The Turkish Online Journal of Educational Technology - TOJET, 1(1), 32-36.

Kim, K. J., Liu, S., \& Bonk, C. J. (2005). Online MBA students' perceptions of online learning: Benefits, challenges and suggestions. The Internet and Higher Education, 8(4), 335-344. http://dx.doi.org/10.1016/j.iheduc.2005.09.005

Matthews, D. B. (1996). An investigation of learning styles and perceived academic achievement for high school students. The Clearing House, 69(4), 249-255.

Mupinga, D. M., Nora, R. T., \& Yaw, D. C. (2006). The learning styles, expectations and needs of online students. College Teaching, 54(1), 185-189. http://dx.doi.org/10.3200/CTCH.54.1.185-189

National Centre for Vocational Education Research. (2002). Flexibility through online Learning: At a glance, Retrieved from http://www.ncver.edu.au/research/proj/nr1F12/nr1F12.pdf 
Özçınar, H., \& Öztürk, E. (2008). Çevrimiçi tartışmalara ilişkin öğrenci görüşleri. Yüzüncü Yıl Üniversitesi Ĕgitim Fakültesi Dergisi, 5(2), 154-178.

Snyder, R. F. (2000). The relationship between learning styles / multiple intelligences and academic achievement of high school students. High School Journal, 83(2), 11-21.

Soo, K. S., \& Bonk, C. J. (1998). Interaction: What does it mean in online distance education?. Paper presented at ED-MEDIA / ED-TELECOM 98 World Conferece (Educational Multimedia and Hypermedia \& World Conferece on Educational Telecommunications), Freiburg, Germany.

Swan, K., Shea, P., Fredericksen, E. E., Pickett, A. M., \& Pelz, W. E. (2000). Course design factors influencing the success of online learning. Paper presented at the WebNet 2000 World Conference on WWW and Internet Proceedings, San Antanio, TX. 